\title{
ANÁLISE DE DISCURSO DO SUJEITO COLETIVO DE CIRURGIÕES-DENTISTAS NO COTIDIANO DA REGULAÇÃO ASSISTENCIAL
}

\author{
Leonardo Carnut ${ }^{1}$, Celso Zilbovicius ${ }^{2}$, Tarsila Teixeira Vilhena Lopes ${ }^{2}$, Brunna Verna Castro ${ }^{3}$ \\ e Jaqueline Vilela Bulgareli ${ }^{4}$ \\ 1Universidade Federal de São Paulo, Brasil, leonardo.carnut@gmail,com \\ ${ }^{2}$ Universidade de São Paulo, Brasil, czilbo@usp.br, tarsilatvlopes@gmail.com \\ ${ }^{3}$ Universidade Estadual do Piauí, Brasil, bvernagondim@hotmail.com \\ ${ }^{4}$ Universidade Federal de Uberlândia, Brasil, jaquelinebulgareli@gmail.com
}

\begin{abstract}
Resumo. Objetivo: Compreender a prática dos cirurgiões-dentistas ao estabelecerem o fluxo assistencial para casos de lesões suspeitas de câncer bucal em um município do nordeste brasileiro. Método: Tratou-se de um estudo qualitativo, do ponto de vista da abordagem do problema de pesquisa. Esses dados foram coletados através de entrevista semiestruturada e analisados segundo o método do Discurso do Sujeito Coletivo. Foram entrevistados quatro Cirurgiões-Dentistas $(C D)$ da rede, dos quais três eram de equipes de saúde bucal e um era a estomatologista do Centro de Especialidades Odontológicas (CEO). Resultados: Os profissionais entendem o fluxo assistencial como parte de sua rotina, no entanto, em ambos os níveis de atenção, Ihes faltam conhecimentos com relação as suas atribuições. Para estes, a referência se resume a uma "fichinha" de encaminhamento e em nenhum momento fazem alusão às demais etapas do fluxo. Segundo eles, sempre existe vaga, mas não há demanda. Isso parece sugerir um problema nesta rede de atenção, com possíveis desdobramentos regionais. Conclusões: Os CD agem indiferentemente à gravidade do problema. A única garantia que o paciente tem é o papel na mão e a esperança de que um dia conseguirá uma marcação, isso quando ele não se perde em face dos problemas comunicacionais.
\end{abstract}

Palavras-chave: Pesquisa Qualitativa; Neoplasia; Sistema Único de Saúde; Regulação e Fiscalização em Saúde.

\section{DISCOURSE ANALYSIS OF THE COLLECTIVE SUBJECT OF DENTAL SURGEONS IN THE DAILY CARE REGULATION}

\begin{abstract}
Objective: To understand the practice of dentists when establishing the assistance flow for cases of suspected oral cancer lesions in a municipality in northeastern Brazil. Method: This was a qualitative study, from the point of view of approaching the research problem. These data were collected through semi-structured interviews and analyzed according to the Collective Subject Discourse method. Four dental surgeons (DS) from the public health system were interviewed, three of whom were from oral health teams and one was a stomatologist at the Dental Specialties Center. Results: Professionals understand the assistance flow as part of their routine, however, at both levels of care, it lack them knowledge about their duties. For these DS, the reference is summarized to a "referral little file" and, even though, they allude to the other stages of the flow. According to them, there is always a vacancy, but there is no demand. This seems to suggest a problem in this network. Conclusions: DSs act regardless of the severity of the problem. The only guarantee that the patient has is the paper in hand and the hope that he will get an appointment, when he is not lost in the face of communication problems.
\end{abstract}

Keywords: Qualitative Research; Neoplasia; Unified Health System; Health Regulation and Inspection. 


\section{INTRODUÇÃO}

A regulação assistencial (ou microrregulação) é uma parte do sistema regulatório (Santos \& Merhy, 2006), que zela pela organização, controle, gerenciamento e priorização do acesso e dos fluxos assistenciais (Brasil, 2010). Compete a ela articular e conjugar as respostas potenciais do sistema, o que implica em avaliar o que foi planejado nos vários recortes da assistência, requerendo da gestão uma inteligência reguladora operacional. Nessa perspectiva, em um sistema assistencialmente regulado, o usuário, ao adentrar a rede de serviços, passa a ser direcionado pelo complexo regulatório, de acordo com suas necessidades (Magalhães, 2002; Batista et al, 2019).

No que se refere, especificamente, ao direcionamento do usuário, um sistema ordenado de fluxos e contrafluxos são necessários para a adequada integração entre "pontos de atenção" de um mesmo sistema. É o que Solla e Chioro (2008) nomeiam como Sistema de referência e contrarreferência, uma parte integrante do processo de regulação assistencial que tem como principal função viabilizar a continuidade da atenção aos usuários (Witt, 1992) gerando, com isso, uma diversidade de fluxos assistenciais. Entende-se por fluxo assistencial o deslocamento da população aos pontos de atenção ou, como chamados normalmente: os serviços de saúde (SESAU, 2003). Este seria, portanto, uma parte constitutiva do Sistema de referência e contrarreferência.

Normativamente, o primeiro documento ministerial que versou sobre o assunto foi a Norma Operacional de Assistência à Saúde 2001-2002 (NOAS 2001/2002) (Brasil, 2001). Focandose no fluxo "atenção básica-atenção secundária", o acesso aos procedimentos especializados, a padronização de solicitação de procedimentos via protocolização e o estabelecimento de unidades de referência inter/intra níveis são ações clássicas na definição de fluxos (Brasil, 2008).

Assim sendo, as unidades de atenção secundária (ou também dita, especializada) compõe, assim como as outras dos demais níveis de atenção, o rol de elementos de um sistema de referência e contrareferência básico (Kurschnir, Chorny \& Lira, 2010). Gerencialmente falando, é importante a organização de fluxos assistenciais que componham um sistema de referência entre atenção básica e atenção secundária que garantam o acesso dos indivíduos às consultas e procedimentos especializados (Solla \& Chioro, 2008). Esse recurso tende a ser mais padronizado quando se trata de casos onde a patologia ou lesão pode progredir para o óbito. No caso dos serviços de saúde bucal, isso fica evidente quando 
a equipe de saúde bucal se depara com uma lesão suspeita de câncer de boca (Maciel, 2012; Santos et al, 2009; Torres-Pereira et al, 2012).

Conceitualmente falando, "câncer de boca", "câncer bucal" e "câncer oral" são termos muito abrangentes, podendo a falta de especificação gerar confusões (Inca, 2012).

Ao se referir ao câncer da cavidade bucal, a Organização Mundial de Saúde, por exemplo, exclui os casos de câncer de lábio. Quanto às demais localizações anatômicas da boca (gengiva, assoalho da boca, mucosa jugal, vestíbulo da boca, língua, palato e área retromolar) diferentes seleções podem ser efetuadas em estudos específicos (Biazevic \& Antunes, 2006).

É responsabilidade do cirurgião-dentista da atenção básica realizar o diagnóstico diferencial de lesões bucais e referenciar o usuário caso a lesão detectada seja suspeita. A portaria ํo 599/GM, de 23 de março de 2006, estabelece que todo Centro de Especialidade Odontológica no Brasil deve realizar, dentre o elenco mínimo, atividades estabelecidas em estomatologia com ênfase no diagnóstico e detecção do câncer bucal (Brasil, 2006b).

Mesmo com a avaliação estomatológica nos Centros Especializados, esta não deve invalidar os esforços dos profissionais para o diagnóstico precoce de doenças bucais nas Unidades Básicas de Saúde no Sistema Único de Saúde (SUS) em todo o Brasil (Brasil, 2006a). Assim sendo, diante destas evidências é que esta pesquisa teve como finalidade compreender a prática dos cirurgiões-dentistas na adoção de certos fluxos assistenciais para os casos de lesões suspeitas de câncer bucal. Do ponto de vista de relacionamento institucional, este projeto esteve filiado ao Campus Arcoverde e Garanhuns da Universidade de Pernambuco assim como à Secretaria Municipal de Saúde a qual já dispôs sua anuência.

\section{METODOLOGIA}

O estudo foi realizado no município de Arcoverde, no estado de Pernambuco, Brasil. Esta municipalidade apresenta $353 \mathrm{Km}^{2}$ de território, tem uma população estimada para 2019 de 74.338 habitantes e se encontra a 256 km de distância da capital do estado de Pernambuco (Recife). Do ponto de vista de rede de serviços de saúde vinculados aos SUS municipal, é composta por 01 Hospital Regional e 19 postos de saúde municipais. 
Especificamente no âmbito dos serviços de saúde bucal, Arcoverde apresenta uma rede de atenção primária com 26 Unidades Básicas de Saúde, com 17 Equipes de Saúde Bucal e 1 Centro de Especialidades Odontológica (Prefeitura Municipal de Arcoverde, 2013).

Cada equipe de saúde bucal cobrem entre 4.000 a 8.000 habitantes conforme descrito nos documentos ministeriais (Brasil, 2006a).

Com as 17 equipes instaladas no município é possível perceber que esta quantidade de equipes abrangem o total do número de habitantes. Do ponto de vista regional, Arcoverde é município sede de uma região de saúde com mais 12 municípios ao redor (Pedra, Venturosa, Buique, Sertânia, Tupanatinga, Custódia, Ibimirim, Manarí, Inajá, Tacaratu, Petrolândia e Jatobá). Apenas Arcoverde, Pedra e Venturosa e Ibimirim apresentam Centros de Especialidades Odontológicas (CEO) próprios, o que, de certa maneira deveriam receber pacientes para tratamento especializado em saúde bucal de outros municípios que não tem CEO em suas redes.

Do ponto de vista da abordagem da pesquisa, tratou-se, portanto, de um estudo qualitativo (Turato, 2003). Esses dados dos discursos dos cirurgiões-dentistas foram coletados por meio de entrevista semi-estruturada (Triviños, 1987) e sistematizados pela técnica de análise dos dados do Discurso do Sujeito Coletivo (Lefèvre et al, 2002).

Do ponto de vista das questões teóricas, tomou-se como "fluxo assistencial" o deslocamento da população aos serviços de saúde (SESAU, 2013).

Esse tipo de deslocamento é um percurso oficialmente normatizado, geralmente fixado por pactuações intergestores e registrados em documentos gerenciais.

$\mathrm{Na}$ ausência destas documentações, em geral os municípios e estados recorrem a padrões estabelecidos por resoluções e/ou portarias das áreas técnicas do Ministério da Saúde.

Para captar a percepção dos entrevistados sobre a categoria e sua execução no cotidiano foi necessária a construção de um tópico-guia que orientou o entrevistador na condução do assunto com o entrevistado (Gaskell, 2010) conforme pode ser visto na figura 1 a seguir. 
Figura 1. Tópico-guia utilizado para as entrevistas com os profissionais da atenção primária. Arcoverde, Pernambuco, Brasil.

Tópico-Guia 1: Roteiro de entrevista para os profissionais cirurgiões-dentistas
$\frac{\text { Identificação }}{\text { Falar seu nome, ano de formação, formação complementar (especializações, mestrado, doutorado) e experiência }}$ clínica prévia ao trabalho em saúde pública
Experiência em saúde pública/saúde da família
Início do trabalho no 'saúde da família' (circunstância do início, motivações para procurar o cargo como forma de
exercício profissional e tempo de exercício)
Dia-a-dia do trabalho clinico no 'saúde da família' (o que mais chama a atenção em relação às capacidades
diagnósticas que o cirurgião-dentista deve ter que difere do setor privado)
Experiência clínica em estomatologia
Atuação na área (monitoria, estágios, áreas correlatas - buco, histologia, patologia)
Segurança clínica no diagnóstico de lesões suspeitas
$\frac{\text { Organização da referência de usuários com lesões suspeitas }}{\text { Descrever como se ocorre a clínica do diagnóstico de lesões suspeitas e como ocorre o fluxo assistencial, desde }}$
o diagnóstico até o atendimento especializado (com detalhes)
$\frac{\text { Responsabilização sanitária pelos usuários com lesões suspeitas }}{\text { Descrever o que ocorre com o paciente após o encaminhamento para o nível especializado }}$
Relatar o que o profissional recebe da gestão como forma de encaminhamento de usuários com lesões suspeitas
para o nível especializado

Fonte: elaboração própria

A entrevista foi realizada por uma única pesquisadora, graduada em odontologia e com vivência nos serviços de saúde, devidamente treinada para realização de entrevistas qualitativas. Para este procedimento de coleta, com este tipo de instrumento não se faz necessária à validação conforme descrito por Gaskell (2010) já que não é intuito do estudo "encaixar" as respostas livres dos sujeitos a categorias previamente estabelecidas em formato questionário e sim criar um ambiente com certo tipo de "informalidade" para que a respostas fossem fluidas e com o mínimo de "engasgos", tentando "provocar" um discurso mais ou menos livre que atendesse aos objetivos da pesquisa (Duarte, 2004).

As entrevistas foram realizadas em um intervalo de 3 semanas. O critério de inclusão para a seleção dos entrevistados foram todos aqueles indivíduos que estavam, no momento da pesquisa, investidos nos cargos de cirurgiões-dentistas de família e cirurgião-dentista especialista em estomatologia ou cirurgia bucomaxilofacial que se dispuseram a participar da pesquisa. De um universo de 18 profissionais, parte desses profissionais (quatro) foram abordados com o intuito de captar a percepção destes sujeitos sobre a questão em estudo. Apenas 4 foram foco desta investigação por serem considerados pela gestão dos serviços os dois extremos da situação de vivência deste fluxo assistencial, 2 deles respeitavam os 
critérios de encaminhamento descritos nos protolocos ministeriais e outros 2 não. O número de entrevistadas realizadas com cada um se deu pela saturação dos discursos (Fontanella, 2012).

A técnica da entrevista semi-estruturada (Britten, 2009), com questões abertas também chamada de semipadronizada (Flick, 2009b) foi escolhida por se adequar ao objetivo desta pesquisa. Essa técnica de entrevista é conduzida com base em uma estrutura flexível, constituindo-se primordialmente de questões abertas que definem a área ser explorada ou pelo menos inicialmente, e a partir da qual o entrevistador ou a pessoa entrevistada podem divergir a fim de prosseguir com uma ideia ou resposta em maiores detalhes (Britten, 2009). Para captar as respostas foram utilizados Mp4 para registro e posterior transcrição.

Após a transcrição das entrevistas em documentos digitais, o material foi organizado no Software Qualiquanti Soft para proceder a análise através do método do Discurso do Sujeito Coletivo (DSC). O software torna mais ágeis tarefas mecânicas da pesquisa e principalmente organiza o trabalho de análise qualitativa realizada pelo pesquisador. Permite o processamento de dados para a análise de recortes discursivos através da criação de um banco de dados que filtra os discursos em estratos e os compara (Lefèvre \& Lefèvre, 2012). Além disso, permite que o próprio pesquisador avalie a qualidade do discurso produzido, aperfeiçoando o recorte dos textos e corrigindo assim desvios e inadequações. Tendo como fundamento a teoria das representações sociais e seus pressupostos sociológicos, a proposta consiste basicamente em analisar o material verbal coletado, extraído de cada um dos depoimentos.

O Discurso do Sujeito Coletivo é uma modalidade de apresentação de resultados de pesquisas qualitativas, que tem depoimentos como matéria prima, sob a forma de um ou vários discursos-síntese escritos na primeira pessoa do singular, expediente que visa expressar o pensamento de uma coletividade, como se esta coletividade fosse o emissor de um discurso, trata-se, portanto, de uma pesquisa de opinião. Esta técnica consiste em selecionar, de cada resposta individual a uma questão, as Expressões-Chave, que são trechos mais significativos destas respostas. A essas Expressões Chaves correspondem Ideias Centrais que são a síntese do conteúdo discursivo manifestado nas Expressões Chaves. Com o material das Expressões Chaves das Ideias Centrais constroem-se discursos-síntese, na primeira pessoa do singular, que são os DSCs, onde o pensamento de 


\section{um grupo ou coletividade emerge como se fosse um discurso individual (Lefèvre \& Lefèvre,}

\section{0) (Quadro 1).}

Quadro 1. Exemplo: Ideia central, expressão chave e devidas ancoragens para a construção do Discurso do Sujeito Coletivo sobre a regulação assistencial do câncer bucal. Arcoverde, Pernambuco, Brasil.

\begin{tabular}{|c|c|c|c|c|}
\hline & IDEIA CENTRAL & EXPRESSÃO CHAVE & ANCORAGEM & EXPRESSÃO CHAVE DA ANCORAGEM \\
\hline \multirow{4}{*}{ 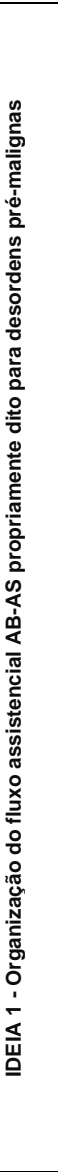 } & $\begin{array}{l}\text { Hipótese diagnóstica- ficha- } \\
\text { entrega da ficha ao paciente- } \\
\text { o paciente busca acesso ao } \\
\text { CEO com a ficha - marcação } \\
\text { no CEO - atendimento no } \\
\text { CEO }\end{array}$ & $\begin{array}{l}\text { "Tá, o paciente chega a gente } \\
\text { faz o diagnóstico, a hipótese } \\
\text { diagnóstica de uma lesão, por } \\
\text { exemplo, aí tem uma fichinha } \\
\text { de encaminhamento a gente } \\
\text { preenche os dados do } \\
\text { paciente, ñ é muito burocrático } \\
\tilde{n} \text { e preenche todos os dados } \\
\text { da fichinha, põe lá ... tem uma } \\
\text { parte, aí a gente entrega ao } \\
\text { paciente o paciente vem } \\
\text { diretamente no CEO e marca, e } \\
\text { aí ele é atendido logo." }\end{array}$ & $\begin{array}{l}\text { "Faz exame e se existir a } \\
\text { necessidade tem } \\
\text { segurança em fazer o } \\
\text { encaminhamento para o } \\
\text { CEO porque lá tem } \\
\text { cirurgião bucomaxilo que } \\
\text { é quem tá habilitado. O } \\
\text { atendimento é rápido de } \\
\text { em caso de necessidade } \\
\text { de cirurgia." }\end{array}$ & $\begin{array}{l}\text { "o paciente chega pra mim pela primeira vez eu faço o } \\
\text { exame clínico todo, então eu procuro manchinha, procuro } \\
\text { ferida, procuro lesão, enfim, paciente que quando vai } \\
\text { contando a história, trabalha levando muito sol, faz toda a } \\
\text { anamnese do paciente, faz exame de lábio, tecido mole, } \\
\text { de língua, de tudo e se existir a necessidade faz o } \\
\text { encaminhamento, é tranquilo nesse sentido assim, até } \\
\text { porque não é a gente que fecha o diagnóstico né!?, eu } \\
\text { me sinto segura em fazer esse encaminhamento, porque } \\
\text { lá tem cirurgião bucomaxilo que é quem tá habilitado } \\
\text { também pra fazer biópsia essa coisa toda, o } \\
\text { procedimento é muito rápido, o tratamento é muito rápido } \\
\text { então quando é caso de urgência, o atendimento é feito } \\
\text { por pronto atendimento...., mas a dificuldade só porque o } \\
\text { dentista não tá todos dias? Então nesses casos de } \\
\text { urgência o atendimento é quase que imediato." }\end{array}$ \\
\hline & $\begin{array}{l}\text { Ficha- hipótese diagnóstico } \\
\text { (?)- especificação da } \\
\text { especialidade: "diagnóstico } \\
\text { oral" - observações sobre o } \\
\text { caso }\end{array}$ & $\begin{array}{l}\text { "Então... Como eu falei: o } \\
\text { paciente vem até a mim, } \\
\text { quando eu observo, eu oriento } \\
\text { e encaminho para o CEO, que } \\
\text { é o centro de especialidades. E } \\
\text { boto o nome na ficha de } \\
\text { encaminhamento, a hipótese } \\
\text { de diagnóstico, interrogação, } \\
\text { coloco lá observações pra } \\
\text { quem for atender dar } \\
\text { importância." }\end{array}$ & $\begin{array}{l}\text { "O profissional precisa } \\
\text { estar atento a qualquer } \\
\text { lesão suspeita Aí a gente } \\
\text { fazia o diagnóstico. assim, } \\
\text { o diagnóstico que não é } \\
\text { exatamente o diagnóstico. } \\
\text { Porque muito é o } \\
\text { patológico, né..." }\end{array}$ & $\begin{array}{l}\text { "É isso aí que eu tô dizendo: você tem que dar importância. } \\
\text { Tem que ir mais fundo, examinar, não deixar assim pra lá: } \\
\text { "Ah, isso vai sair". Isso vai desaparecer". Não é assim. Tem } \\
\text { que ir atrás, tem que examinar, tem que fazer anamnese } \\
\text { direito, ver se ele é fumante, se é agricultor, que acontece } \\
\text { muito, leva muito sol. E aí você tem que examinar melhor, } \\
\text { é isso que é a diferença. A gente não pode dizer já que é } \\
\text { um tipo de lesão, que não é. Isso é uma hipótese de } \\
\text { diagnóstico. Porque são vários fatores que ajudam a você } \\
\text { chegar no diagnóstico... É o radiológico, tem que tirar } \\
\text { radiografia, fazer exame, biópsia." }\end{array}$ \\
\hline & $\begin{array}{l}\text { Ficha- ida ao CEO - agendar } \\
\text { a consulta }\end{array}$ & $\begin{array}{l}\text { "essa ficha aqui a gente } \\
\text { preenche... certo? Uma vez } \\
\text { preenchido, carimbado aqui, } \\
\text { ele vai imediatamente lá ao } \\
\text { CEO e faz a, agenda a } \\
\text { consulta, né? Aí ele faz o } \\
\text { agendamento lá, data, hora e o } \\
\text { paciente já vai para ser } \\
\text { atendido. É encaminhado direto } \\
\text { daqui da Unidade Básica de } \\
\text { Saúde para o Centro } \\
\text { Especializado e lá eles } \\
\text { resolvem." }\end{array}$ & $\begin{array}{l}\text { "Qualquer lesão que } \\
\text { desconfie encaminha, } \\
\text { pois não realiza } \\
\text { diagnóstico na atenção } \\
\text { básica." }\end{array}$ & $\begin{array}{l}\text { "Qualquer lesão que eu desconfie uma feridinha, alguma } \\
\text { lesão que não sare, que já venha há algum tempo e sem } \\
\text { resultados, mais de três meses, quatro meses, eu faço } \\
\text { imediatamente o encaminhamento. Eu acho melhor pecar } \\
\text { por excesso. Qualquer lesão que eu não identifique e que } \\
\text { precise ser retirado, eu encaminho porque aqui a gente } \\
\text { não faz esse serviço de retirada, seja que lesão for, aí faz } \\
\text { o encaminhamento porque lá é retirado e ela lá vê se tem } \\
\text { a necessidade ou não de mandar para a biopsia." }\end{array}$ \\
\hline & $\begin{array}{l}\text { Paciente marcado com o } \\
\text { papel vindo da Atenção } \\
\text { Básica }\end{array}$ & $\begin{array}{l}\text { "Na verdade, eu só recebo o } \\
\text { paciente com o papel, com a } \\
\text { referência em mãos e, na } \\
\text { maioria das vezes, não tem } \\
\text { muita orientação." }\end{array}$ & $\begin{array}{l}\text { "Não sabe como funciona } \\
\text { a referência porque não } \\
\text { faz, dá andamento a partir } \\
\text { da referência, e percebe } \\
\text { que a atenção básica não } \\
\text { tem segurança de } \\
\text { orientar." }\end{array}$ & $\begin{array}{l}\text { "Detalhadamente é meio complicado, porque não sou eu } \\
\text { que faço essa referência, a gente tem até os protocolos, a } \\
\text { gente trabalha com os protocolos de referência para o } \\
\text { CEO, que a atenção básica tem. Âs vezes percebe que } \\
\text { não tem muito essa segurança da atenção básica de se } \\
\text { estar orientando, já manda e não fala muita coisa e aqui a } \\
\text { gente tem que começar a orientar. Com a referência, a } \\
\text { gente dá andamento ao que precisa ser feito." }\end{array}$ \\
\hline \multirow{2}{*}{ 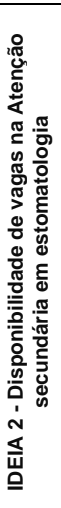 } & $\begin{array}{l}\text { Não há cota de atendimento } \\
\text { na Atenção Secundária. }\end{array}$ & $\begin{array}{l}\text { "Não, assim não aquele } \\
\text { número que tem q mandar, } \\
\text { quando aparece a gente } \\
\text { manda, mas como eu falei na } \\
\text { minha rotina eu não } \\
\text { encaminhei nenhum como } \\
\text { suspeita de lesão cancerígena. } \\
\text { Mas se precisar não tem essa } \\
\text { quantidade limite a gente não } \\
\text { tem uma quantidade fixa pré- } \\
\text { determinada de } \\
\text { encaminhamento mensal não. } \\
\text { É segundo a demanda, até } \\
\text { porque não é tanto." }\end{array}$ & $\begin{array}{l}\text { "Não tem quantidade de } \\
\text { fichas, quando o paciente } \\
\text { precisa logo é atendido, } \\
\text { se for urgência o } \\
\text { atendimento é rápido, } \\
\text { mas lesões pré } \\
\text { cancerígenas r não } \\
\text { aparece." }\end{array}$ & $\begin{array}{l}\text { "Não tem quantidade de pessoas, assim não aquele } \\
\text { número que tem q mandar, quando aparece a gente } \\
\text { manda. mas se precisar não tem essa quantidade limite } \\
\text { não pra encaminhar. Mas se precisar o paciente vem } \\
\text { diretamente no CEO e marca, e aí ele é atendido logo no } \\
\text { CEO ele é examinado, se for em caso de urgência o } \\
\text { atendimento é de pronto, é um atendimento rápido. E } \\
\text { lesões pré-cancerígenas pra encaminhar pro CEO } \\
\text { realmente quase ñ aparece, na verdade ñ aparece num é... } \\
\text { pelo menos lá não é da rotina." }\end{array}$ \\
\hline & Há sempre vaga & "Sempre, sempre existe vaga!" & $\begin{array}{l}\text { "Qualquer lesão } \\
\text { encaminha, pois sempre } \\
\text { há vaga. O paciente } \\
\text { consegue ficha e o centro } \\
\text { especializado é quem } \\
\text { resolve o problema." }\end{array}$ & $\begin{array}{l}\text { "Qualquer lesão que eu desconfie, eu faço imediatamente o } \\
\text { encaminhamento. Eu acho melhor pecar por excesso, uma } \\
\text { vez preenchido, carimbado aqui, ele vai imediatamente lá } \\
\text { ao CEO e faz a, agenda a consulta, né. Aí ele faz o } \\
\text { agendamento lá, data, hora e o paciente já vai para ser } \\
\text { atendido, é encaminhado direto daqui da Unidade Básica } \\
\text { de Saúde para o Centro Especializado e lá eles resolvem." }\end{array}$ \\
\hline
\end{tabular}

Fonte: pesquisa direta 


\section{RESULTADOS E DISCUSSÃO}

\subsection{As duas ideias de fluxo assistencial}

O fluxo assistencial ordenado direciona o usuário para o atendimento que ele necessita e garante acesso a todos os níveis de atenção que o problema exige. A partir dos discursos dos profissionais percebemos que há um consenso quanto a compreensão dos mesmos sobre o fluxo assistencial. Este é resumido e citado em todas as ideias centrais como uma "ficha" ou "fichinha" conforme preferem chamar:

"Tá, o paciente chega a gente faz o diagnóstico, a hipótese diagnóstica de uma lesão, por exemplo, aí tem uma fichinha de encaminhamento a gente preenche os dados do paciente, não é muito burocrático não e preenche todos os dados da fichinha, põe lá ... tem uma parte , aí a gente entrega ao paciente o paciente vem diretamente no CEO e marca, e aí ele é atendido logo." (CD 1).

"essa ficha aqui a gente preenche... certo? Uma vez preenchido, carimbado aqui, ele vai imediatamente lá ao CEO e faz a, agenda a consulta, né? Aí ele faz o agendamento lá, data, hora e o paciente já vai para ser atendido. É encaminhado direto daqui da Unidade Básica de Saúde para o Centro Especializado e lá eles resolvem." (CD 2).

A questão fundamental é se esses pacientes estão chegando ao nível de atenção mais especializado, e quando conseguem acessar, não são devidamente orientados. Os discursos apontam que os profissionais da atenção básica não percebam a responsabilidade de suas atribuições relacionadas ao diagnóstico diferencial de lesões suspeitas de câncer bucal, conforme elencado nos documentos oficiais (Brasil, 2006a) e prosseguem afirmando que o profissional que está mais habilitado para esse tipo de exame é o cirurgião bucomaxilofacial.

“... eu me sinto segura em fazer esse encaminhamento, porque lá tem cirurgião bucomaxilo que é quem tá habilitado também pra fazer biópsia essa coisa toda." (CD 3)

A compreensão dos cirurgiões-dentistas sobre o funcionamento do fluxo assistencial otimiza o trabalho dos demais níveis de atenção por direcionar o paciente de acordo com sua necessidade (Cavalcanti, 2013) quando o profissional utiliza toda sua capacidade diagnóstica no âmbito de seu trabalho na atenção básica, os serviços mais especializados não ficam sufocados com casos que poderiam ser resolvidos neste nível de atenção.

Contudo, uma ideia que emerge nos discursos dos cirurgiões-dentistas é que são poucos os casos e que sempre há vagas disponíveis na atenção secundária, sendo possível perceber 
em seus discursos que os mesmos acham desnecessário um fluxo assistencial com os parâmetros clínico-gerenciais adequados.

"Não, assim não aquele número que tem q mandar, quando aparece a gente manda, mas como eu falei na minha rotina eu não encaminhei nenhum como suspeita de lesão cancerígena. Mas se precisar não tem essa quantidade limite a gente não tem uma quantidade fixa pré-determinada de encaminhamento mensal não. É segundo a demanda, até porque não é tanto." (CD 3)

Esse tipo de discurso parece mascarar uma questão ainda mais grave: a suposta 'inexistência de pacientes com lesões suspeitas'. Isso parece contraditório com a literatura, pois, segundo Narvai e Frazão (2006) o câncer de boca está entre os agravos à saúde bucal considerados como emergentes, podendo sugerir, portanto, que o diagnóstico precoce das lesões potencialmente malignas não está sendo realizado.

Os estudos na área de regulação assistencial afirmam que, mesmo sob uma aparente demanda reduzida é fundamental que os serviços maximizem suas possibilidades de intervenção para racionalizar a busca por cuidado em outros pontos de atenção (Baduy et al, 2011; Mendes, 2010). Mesmo assim, a capacidade técnica do profissional é seriamente posta em "xeque" na questão da regulação. Mesmo sob esta prerrogativa, se o profissional não sentir segurança clínica no procedimento a tendência é que o mesmo encaminhe o usuário, subutilizando o espaço da atenção básica para este tipo de serviço.

"Qualquer lesão que eu desconfie, eu faço imediatamente o encaminhamento. Eu acho melhor pecar por excesso, uma vez preenchido, carimbado aqui, ele vai imediatamente lá ao CEO e faz a, agenda a consulta, né. Aí ele faz o agendamento lá, data, hora e o paciente já vai para ser atendido, é encaminhado direto daqui da Unidade Básica de Saúde para o Centro Especializado e lá eles resolvem." (CD 3)

Fica evidente no discurso do CD 3 o comprometimento do acesso aos serviços especializados traduzidos em uma série de marcações que faz com que o paciente se perca em meio idas e voltas sem solução, haja vista que o usuário deve aventurar-se na busca de um acesso a um outro serviço cujas barreiras já são bem descritas na literatura (Travassos \& Martins, 2004) inviabilizando assim, a integralidade da assistência. O caminho que o usuário percorre entre a atenção básica e a secundária aparentemente não é protegido por nenhuma estratégia gerencial de regulação que garanta e monitore o acesso ao nível especializado. Esse aspecto denota a ausência de responsabilidade sanitária dos profissionais para com o trânsito do usuário interunidades explícito também no discurso abaixo. 
"Na verdade, eu só recebo o paciente com o papel, com a referência em mãos e, na maioria das vezes, não tem muita orientação." (CD 4).

Conforme podemos ver nos resultados as expressões chave das ideias centrais mostram a visão do cirurgião-dentista da atenção básica assim como do Centro de Especialidades Odontológicas, em ambos os casos a ideia de fluxo é simplista. A ideia é compreender como se organiza a construção dos Discursos do Sujeito Coletivo sobre este tema a partir das figuras verbais que se referem aos trechos mais significativos que remontam o discurso deste coletivo em uma 'primeira pessoa'.

\subsection{A síntese qualitativa da compreensão sobre o fluxo assistencial}

Quando sintetizados qualitativamente, pode-se obter uma percepção ampliada da coletividade sobre o programa em um único discurso que se refere a representação social daquilo que os cirurgiões-dentistas pensam sobre a regulação do fluxo assistencial dos casos de câncer de boca.

Quadro 2. Construção do Discurso do Sujeito Coletivo sobre a regulação assistencial do câncer bucal. Arcoverde, Pernambuco, Brasil.

\begin{tabular}{|c|c|c|}
\hline & IDEIA CENTRAL & EXPRESSĀO-CHAVE \\
\hline & $\begin{array}{l}\text { Tá, o paciente chega, a gente faz o diagnóstico, a } \\
\text { hipótese diagnóstica de uma lesão, por exemplo, aí } \\
\text { tem uma fichinha de encaminhamento, a gente } \\
\text { preenche os dados do paciente, não é muito } \\
\text { burocrático e preenche todos os dados da fichinha, } \\
\text { põe lá.... tem uma parte, que entrega ao paciente } \\
\text { que vai diretamente ao CEO e marca, e aí ele é } \\
\text { atendido logo." "Então... Como eu falei: o paciente } \\
\text { vem até a mim, quando eu observo, eu oriento e } \\
\text { encaminho para o CEO, que é o centro de } \\
\text { especialidades. E boto o nome na ficha de } \\
\text { encaminhamento, a hipótese de diagnóstico, } \\
\text { interrogação, coloco lá observações pra quem for } \\
\text { atender dar importância." essa ficha aqui a gente } \\
\text { preenche... certo? Uma vez preenchido, carimbado } \\
\text { aqui, ele vai imediatamente lá ao CEO e faz a, } \\
\text { agenda a consulta, né? Aí ele faz o agendamento } \\
\text { lá, data, hora e o paciente já vai para ser atendido. } \\
\text { É encaminhado direto daqui da Unidade Básica de } \\
\text { Saúde para o Centro Especializado e lá eles } \\
\text { resolvem." "Na verdade, eu só recebo o paciente } \\
\text { com o papel, com a referência em mãos e, na } \\
\text { maioria das vezes, não tem muita orientação. " }\end{array}$ & 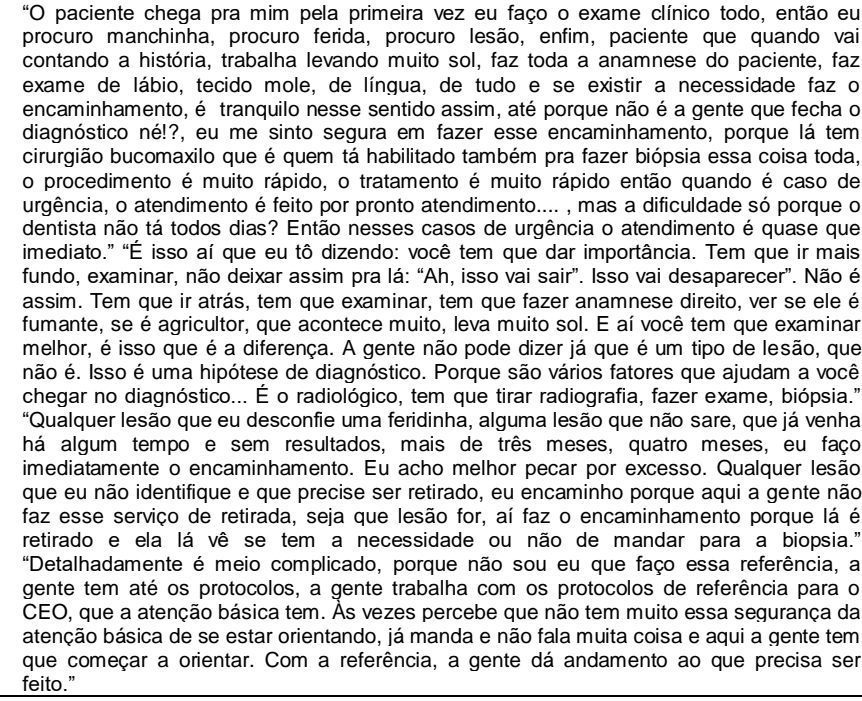 \\
\hline & $\begin{array}{l}\text { "Não, assim não aquele número que tem q mandar, } \\
\text { quando aparece a gente manda, mas como eu falei } \\
\text { na minha rotina eu não encaminhei nenhum como } \\
\text { suspeita de lesão cancerígena. Mas se precisar não } \\
\text { tem essa quantidade limite a gente não tem uma } \\
\text { quantidade fixa pré-determinada de } \\
\text { encaminhamento mensal não. É segundo a } \\
\text { demanda, até porque não é tanto." Sempre, sempre } \\
\text { existe vaga! }\end{array}$ & $\begin{array}{l}\text { "Não tem quantidade de pessoas, assim não aquele número que tem q mandar, quando } \\
\text { aparece a gente manda. mas se precisar não tem essa quantidade limite não pra } \\
\text { encaminhar. Mas se precisar o paciente vem diretamente no CEO e marca, e aí ele é } \\
\text { atendido logo no CEO ele é examinado, se for em caso de urgência o atendimento é de } \\
\text { pronto, é um atendimento rápido. E lesões pré-cancerígenas pra encaminhar pro CEO } \\
\text { realmente quase ñ aparece, na verdade ñ aparece num é... pelo menos lá não é da rotina." } \\
\text { "Qualquer lesão que eu desconfie, eu faço imediatamente o encaminhamento. Eu acho } \\
\text { melhor pecar por excesso, uma vez preenchido, carimbado aqui, ele vai imediatamente lá } \\
\text { ao CEO e faz a, agenda a consulta, né. Aí ele faz o agendamento lá, data, hora e o o } \\
\text { paciente já vai para ser atendido, é encaminhado direto daqui da Unidade Básica de Saúde } \\
\text { para o Centro Especializado e lá eles resolvem." }\end{array}$ \\
\hline
\end{tabular}

Fonte: pesquisa direta 
Assim, o discurso do sujeito coletivo que versa sobre a compreensão do fluxo assistencial entre atenção básica e atenção secundária para lesões suspeitas de câncer de boca (desordens potencialmente malignas na cavidade bucal) apresenta-se conforme o quadro 2.

\section{CONSIDERAÇÕES FINAIS}

Através dos achados dessa pesquisa pode se classificar duas formas de compreensão diferentes que os cirurgiões-dentistas pesquisados apresentam sobre o fluxo assistencial. Uma primeira restrita a uma ficha de encaminhamento que denota a simplificação que o direcionamento do usuário apresenta quando se trata do cuidado voltado ao diagnóstico de lesões suspeitas de câncer de boca. Outra, apoia-se na ideia da farta disponibilidade de vagas e poucos casos identificados. Esta compreensão por sua vez abre espaço para a especulação sobre a execução do papel do cirurgião-dentista em relação ao diagnóstico precoce assim como a baixa responsabilização sanitária pela captação e direcionamento do cuidado à nível especializado repercutindo assim, na garantia do acesso.

Nessa conjuntura, é possível afirmar que, para os profissionais que foram alvos dessa investigação, os fluxos assistenciais adotados são reflexos dos mínimos esforços na condução dos casos, seja, porque não Ihes trazem segurança diagnóstica, sejam porque estes refletem a incapacidade que os atores envolvidos nesse fluxo têm em constituírem uma rede. Parece que para o usuário, a única garantia é o papel na mão e a esperança de que um dia conseguirá uma marcação, isso quando ele não se perde em face dos problemas comunicacionais. Neste contexto hostil, torna-se mais fácil desistir dessa empreitada e torcer para que o tempo lhes seja gentil.

\section{REFERÊNCIAS}

Baduy RS, Feuerwerker LCM, Zucolli M \& Borian JT. (2011). A regulação assistencial e a produção do cuidado: um arranjo potente para qualificar a atenção. Cad. Saúde Pública. 27 (2), 295-304.

Biazevic MGH \& Antunes JLF. Câncer bucal. In: Antunes JLF \& Peres MA. (2006). Fundamentos de Odontologia - Epidemiologia da saúde bucal. Rio de Janeiro: Guanabara Koogan, p. 180-192.

Brasil. (2001). Ministério da Saúde. Portaria no. 267, de 26 de janeiro de 2001 (Norma Operacional da Assistência à Saúde - NOAS/2001) Diário Oficial da República Federativa do Brasil, Brasília, DF, 29 jan, 2001.

Brasil. (2006a). Ministério da Saúde. Secretaria de Atenção à Saúde, Departamento de Atenção Básica. Brasília: Ministério da Saúde, 2006. Departamento de Atenção Básica. - Brasília: Ministério da Saúde, 2006a. 92 p. il. - (Cadernos de Atenção Básica, n. 17) (Série A. Normas e Manuais Técnicos).

Brasil. (2008). Portaria GM no. 1.559, de 1ำ de agosto de 2008. Institui a Política Nacional de Regulação do Sistema Único de Saúde - SUS. Brasília - DF. 
Brasil. (2010). Portaria no. 4.279 de 30 de dezembro de 2010. Estabelece diretrizes para organização da Rede de Atenção à Saúde no âmbito do Sistema Único de Saúde. Brasília - DF.

Brasil. (2006b). Portaria no. 599/GM de 23 de março de 2006b. Define a implantação de Especialidades Odontológicas (CEOs) e de Laboratórios Regionais de Próteses Dentárias (LRPDs) e estabelecer critérios, normas e requisitos para seu credenciamento. Brasília - DF.

Batista SR. (2019). O complexo regulador em saúde do Distrito Federal, Brasil, e o desafio da integração entre os níveis assistenciais, Brasília-DF, Brasil. Ciência \& Saúde Coletiva, 24 (6), 2043-2052.

Britten N. (2009). Entrevistas qualitativas. In: Pope C, Mays N. Pesquisa qualitativa na atenção à saúde. 3a ed. São Paulo: Editora Artmed: p. 23-32.

Cavalcanti RP et al. (2013). Absenteísmo de consultas especializadas no sistema de saúde público: relação entre causas e o processo de trabalho de equipes de saúde da família, João Pessoa - PB, Brasil. Tempus - Actas de Saúde Coletiva, 63-84.

CFA-SUS. (2013). Controle de Fluxo Assistencial do Sistema Único de Saúde. Acessado em: 25/01/2013. Disponível em: http://www.rafe.com.br/index_site/ regionalizacao.asp

Duarte R. (2004). Entrevistas em pesquisas qualitativas. Educar, 24, p. 213-225.

Fontanella BJB \& Júnior RM. (2012). Saturação teórica em pesquisas qualitativas: contribuições psicanalíticas. Psicol. Estud., 17 (1), 63-71.

Flick U. Entrevistas. (2009b). In: Introdução a pesquisa qualitativa. São Paulo: Editora Artmed: 3ª . Edição, 143-166.

Gaskell G. (2010). Entrevistas individuais e grupais. Bauer MW, Gaskell G. Pesquisa qualitativa com texto, imagem e som - Um manual prático. 8a ed. Petrópolis, Rio de Janeiro: Editora Vozes, 64-89.

Instituto Nacional de Câncer José Alencar Gomes da Silva (INCA). (2012). Coordenação Geral de Ações Estratégicas. Coordenação de Prevenção e Vigilância. Estimativa 2012: incidência de câncer no Brasil / Instituto Nacional de Câncer José Alencar Gomes da Silva, Coordenação Geral de Ações Estratégicas, Coordenação de Prevenção e Vigilância. - Rio de Janeiro: Inca, 2011. 118 p.

Lefèvre AMC et al. (2002). Assistência pública à saúde no Brasil: estudo de seis ancoragens. Saúde e Sociedade 11 (2), 35-47.

Lefèvre F \& Lefèvre AMC. (2012). Pesquisa de Representação Social: um enfoque qualiquantitativo, 2 ed., Brasília: Liber Livro, 2012.

Lefèvre F, Lefèvre AMC \& Teixeira JJV. O discurso do sujeito coletivo: uma nova abordagem metodológica em pesquisa qualitativa. Caxias do Sul: EDUCS, 2000.

Maciel SSSV. (2012). Morbimortalidade por cânceres da boca e faringe em capitais brasileiras. Revista da AMRIGS 56 (1), 38-45.

Magalhães Jr HM. (2002). Regulação assistencial: a busca de novas ferramentas no SUS para enfrentar o desafio de garantir a assistência com equidade. Belo Horizonte: Prefeitura Municipal, 2002. (Pensar BH política social).

Mendes EV. (2010). As redes de atenção à saúde. Ciênc. saúde coletiva 15(5), 2297-2305.

Narvai PC \& Frazão P. (2008). Problemas de Saúde Bucal. In: Saúde bucal no Brasil: muito além do céu da boca. Rio de Janeiro: Editora Fiocruz, 21-45.

Prefeitura Municipal de Arcoverde. (2013). Acessado em 21/01/2013. Disponível em: http://www.arcoverde.pe.gov.br/arcoverde.php?id=3 
Santos FP \& Merhy EE. (2006). Public regulation of the health care system in Brazil - a review. Interface Comunic., Saúde, Educ. 10 (19), 25-41.

Santos LCO et al. (2009). Câncer bucal: amostra populacional do estado de Alagoas em hospital de referência. Braz J Otorhinolaryngol 75 (4), 524-9.

SESAU. (2013). Secretaria do Estado de Saúde de Alagoas. Superintendência de Gestão e Participação social. Resumo do processo de elaboração do Plano Diretor de Regionalização da saúde - PDR. Acessado em: 25/01/2013. Disponível em: http :www.saude.al.gov.br/sites/default/files/pdri-_nota_tecnica_revisao_alagoas_0.pdf.

Solla J \& Chioro A. (2008). Atenção ambulatorial especializada. In: Giovanella L. et al (orgs). Políticas e sistemas de saúde no Brasil. Editora: Fiocruz, 627-664.

Torres-Pereira C et al. (2012). Abordagem do câncer da boca: uma estratégia para os níveis primário e secundário de atenção em saúde. Cad. Saúde Pública 28 (Sup), S30-S39.

Travassos C, Martins M. (2004). Uma revisão sobre os conceitos de acesso e utilização de serviços de saúde. Cad. Saúde Pública 20(Sup 2). S190-S198.

Triviños ANS. (1987). Introdução à pesquisa em ciências sociais: a pesquisa qualitativa em educação. São Paulo: Atlas.

Turato ER. (2003). Tratado da metodologia da pesquisa clínico-qualitativa. Petrópolis RJ.: Editora Vozes.

Witt RR. (1992). Sistema de referência e contra-referência num serviço de saúde comunitária. Rev Gaúcha Enf. $13(1), 19-23$. 